MEDIALOG: Jurnal IImu Komunikasi, Volume III, No. II, Agustus 2020, hlm 107-112

\title{
KOMUNIKASI PERSUASI HUMAS DIREKTORAT JENDERAL PAJAK MELALUI SEMINAR PAJAK BERTUTUR PADA MAHASISWA UNIVERSITAS NASIONAL JAKARTA
}

\author{
Muhammad Infaqi Junaedi ${ }^{1}$ \\ Jurusan Ilmu Komunikasi, Hubungan Masyarakat, The London School of Public Relations, Jakarta \\ Email: junainfaqi@gmail.com
}

\begin{abstract}
ABSTRAK
Pendapatan Negara di Indonesia mengalami penurunan di dalam membayar pajak. Hal itu mendorong Humas Direktorat Jenderal Pajak untuk mensosialisasikan sadar pajak salah satunya melalui seminar pajak bertutur, dalam memberikan informasi humas direktorat Jenderal Pajak tidak terlepas dari proeses komunikiasi persuasi yang di gunakan untuk mempengaruhi audience. Penelitian ini menggunakan metodelogi kualitatif. Teori yang digunakan adalah teori komunikasi persuasi Hovland/Yale oleh Perloff. Adapun tujuan dari penelitian ini adalah untuk mengetahui Bagaimana komunikasi persuasi Humas Direktorat Jenderal Pajak melalui seminar pajak bertutur pada mahasiswa Universitas Nasional Jakarta. Teknik pengumpulan data primer yang dilakukan adalah dengan menggunakan wawancara terstruktur. Kemudian data sekunder diperoleh melalui studi kepustakaan untuk memperoleh data dari buku, internet dan website. Selain itu, data sekunder juga diperoleh dari data internal Humas Direktorat Jenderal Pajak. Berdasarkan hasil penelitian, diketahui bahwa Komunikasi persuasi yang di gunakan oleh Direktorat Jenderal Pajak melalui seminar pajak bertutur pada mahaisiswa Universitas Nasional Jakarta sesuai dengan tahapan proses komunikasi persuasi.
\end{abstract}

Kata Kunci: Komunikasi Persuasi, Direktorat Jenderal Pajak, Pajak Bertutur, Sosialisasi, Mahasiswa, Universitas Nasional

\section{PERSUASIVE COMMUNICATION OF PUBLIC RELATIONS DIRECTORATE GENERAL OF TAXATION THROUGH A SEMINAR TAXES TOLD THE STUDENTS OF THE NASIONAL UNIVERSITY OF JAKARTA}

\begin{abstract}
State revenue in Indonesia has decreased in paying taxes. It encourages the Public Relations Directorate General of Taxation to disseminate the tax-conscious one of them through tax seminar speaks, in providing public relations information Directorate General of Taxes is inseparable from the communication persuasive process that is used to influence the audience. This research uses qualitative descriptive methodology. The theory used is the theory of persuasive communication of Hovland / Yale by Perloff. The purpose of this study is to find out how the Persuasive Communication of Public Relations Directorate General of Taxation through a seminar taxes told the students of the Nasional University of Jakarta. Primary data collection techniques are done by using structured interviews. Then the secondary data obtained through literature study to obtain data from books, internet and website. In addition, secondary data is also obtained from the internal data of the Directorate General of Taxation Public Relations. Based on the results of the research, it is known that the persuasive communication that is used by the Directorate General of Taxes through tax seminars told the student National University of Jakarta in accordance with the stages of the persuasion communication process
\end{abstract}

Keywords: Directorate General of taxes, government public relations, student, National University, Persuasive Communication 
Korespondensi: Muhammad Infaqi Junaedi S.Ikom. The London School of Public Relations Jakarta. Sudirman Park Campus Jl. K.H. Mas Mansyur Kav.35 Jakarta Pusat 10220, Indonesia. No. Hp, Whatsapp: 081282769697 Email:Junainfaqi@gmail.com

\section{PENDAHULUAN}

Setiap Negara memiliki aturan yang berlaku, terutama dalam bidang perpajakan. Karena pajak merupakan sumber utama pendapatan negara. Maka itu pajak sangat diperlukan bagi setiap negara. Pajak yang telah di berikan kepada Negara tersebut akan mengembalikanya kembali dalam bentuk pembangunan yang berkaitan dengan kepentingan umum.

Pembayaran pajak merupakan perwujudan dari kewajiban kenegaraan dan peran serta Wajib Pajak untuk secara langsung dan bersama-sama melaksanakan kewajiban perpajakan untuk pembiayaan negara dan pembangunan nasional. Sesuai falsafah undang-undang perpajakan, membayar pajak bukan hanya merupakan kewajiban, tetapi merupakan hak dari setiap warga Negara untuk ikut berpartisipasi dalam bentuk peran serta terhadap pembiayaan negara dan pembangunan nasional (DJP: 2012).

Berbagai cara Humas Direktorat Jenderal Pajak melakukan sosialisasi kepada masyarakat agar mereka mengetahui apa itu pajak, dan manfaat bagi diri sendiri dan bagi negara nya. Ada beberapa cara Humas Direktorat Jenderal Pajak mensosialisasikan program sadar pajak ini kepada masyarakat diantaranya seperti melakukan seminar, sosial media campaign, Program Pajak bertutur, menggunakan tagline dan lain sebagainya.

Dari beberapa tools atau cara yang di gunakan Humas Direktorat Jenderal Pajak, peneliti memilih lebih fokus untuk meneliti Seminar pajak Bertutur.
Program ini merupakan upaya bersama Direktorat Jenderal Pajak dengan Kemendikbud dan Kemenristek Dikti selaku pihak yang membidangi pendidikan untuk menanamkan kesadaran pajak kepada peserta didik dan tenaga pendidik melalui integrasi materi kesadaran pajak dalam Pendidikan. Integrasi kedua program pemerintah tersebut diwujudkan dengan penandatanganan Nota Kesepahaman antara Kemenkeu dan Kemendikbud Nomor: MoU-21/MK.03/2014 dan Nomor: 13/X/NK/2014 tentang Peningkatan Kesadaran Pajak melalui Pendidikan. (Wibowo: 2017)

Data penerimaan pajak tahun 2013 sampai tahun 2016 menurut (DJP: 2017) mengalami penurunan, capaian tahun 2013 yaitu 92,57\%, 2014 91,56\%, 2015 81,96\% dan 2016 mencapai $81,60 \%$. Dilihat dari data tersebut kesadaran masyarakat membayar pajak masih rendah dan ditambah penargetkan pendapatan Negara tahun 2018 sangat besar maka peran pemerintah khususnya Direktorat Jenderal Pajak memiliki tugas besar agar 10 tahun mendatang semua masyarakat terutama generasi muda semua bisa aktif lapor pajak.

Maka itu pentingnya sosialisasi melalui seminar ini agar para peserta seminar ini memiliki rasa kesadaran membayar pajak yang di tanamkan sejak usia muda, sehingga ketika mereka dewasa kesadaran itu muncul dengan melakukan kewajiban mereka yaitu membayar pajak.

Sebagai implementasi dari program ini, Direktorat Jenderal Pajak menyelenggarakan 
kegiatan "Pajak Bertutur" untuk yang pertama kalinya dengan target minimal 110.000 siswa yang diselenggarakan pada 11 Agustus 2017. Pesan kunci (key message) yang akan disampaikan adalah nilai-nilai "Berbagi dan Gotong Royong" bagi siswa SD. "Pajak sebagai pelaksanaan Hak dan Kewajiban sebagai Warga Negara" bagi siswa SMP, "Pajak sebagai Tulang Punggung Pembangunan” bagi siswa SMA, dan "Pajak sebagai perwujudan Ipoleksosbudhankam "bagi mahasiswa Perguruan Tinggi. Apabila setiap tahun "Pajak Bertutur" dilaksanakan secara konsisten, bukan tidak mungkin akan terwujud generasi emas 2045 yang Sadar Pajak. (Wibowo :2017).

Dalam pelaksanaan sosialisasinya Humas Direktorat Jenderal Pajak sesuai dengan Fungsi Public Relations dapat diwujudkan melalui beberapa strategi humas (Ruslan, 2007:142) yaitu: 1. Strategi opersional 2. Pendekatan Persuasif dan edukatif 3. Pendekatan tanggung jawab sosial humas dan pendekatan kerjasama.

Maka dari itu hal tersebut tidak terlepas dari teknik komunikasi persuasi yang digunakan untuk mempengaruhi mahasiswa agar sadar akan pentingnya pajak, komunikasi persuasi didefinisikan sebagai "perubahan sikap akibat paparan informasi dari orang lain" (Severin \& Tankard :2007). Adapun tujuan komunikasi persuasif secara bertingkat ada dua De Vito dalam (Riyanto \& Mahfud: 2012) yaitu; (1) mengubah atau menguatkan keyakinan (believe) dan sikap (attitude) audiens, (2) mendorong audiens melakukan sesuatu/memiliki tingkah laku (behaviour) tertentu yang diharapkan. Komunikasi Persuasi Humas Direktorat Jenderal Pajak Melalui Seminar Pajak Bertutur Pada Mahasiswa Universitas
Hal tersebut juga di kemukaan oleh (Syamsurizal :2016) Strategi yang bersifat persuasif juga dibutuhkan dalam melakukan kegiatan karena masih adanya pandangan yang negative dari audience. Untuk tahapan, ada baiknya jika audience memahami terlebih dahulu latar belakang dan kelebihan-kelebiahan di suatu Instansi

Sedangkan menurut (Rakhmat, 2008:14) komunikasi persuasive diartikan sebagai "Suatu proses untuk mempengaruhi pendapat, sikap dan tindakan orang dengan menggunakan manipulasi psikologis sehingga orang tersebut bertindak seperti atas kehendaknya sendiri". Selain itu, komunikasi persuasif juga diartikan sebagai komunikasi yang dilakukan sebagai ajakan atau bujukan agar mau bertindak sesuai dengan keinginan (Brata, 2003:70)

Dalam melakukan komunikasi persuasi memiliki sebuah proses, menurut (Perloff, 2003:121) dalam bukunya Dynamics of Perssuasion bahwa konsep mengenai proses komunikasi persuasif yang berfokus pada pembelajaran dan motivasi. Untuk dapat terpengaruh oleh komunikasi persuasif, seseorang harus memerhatikan, memahami, mempelajari, menerima dan menyimpan pesan persuasi tersebut.

Lalu di jelaskan bahwa di dalam proeses komunkasi persuasi memliki tahapan dimana persuade mempelajari pesan dari persuader. Dalam proses tersebut terdapat beberapa tahapan, yakni attention (perhatian), comprehension (pemahaman), learning (belajar), acceptance (penerimaan), dan retention (penyimpanan). Tahapan yang dikemukakan Hovland ini Nasional Jakarta 
merupakan proses sebelum persuadee akhirnya memutuskan untuk merubah sikapnya, setelah mendapatkan paparan informasi atau argumen dari persuader (Perloff :2003)

Dengan adanya masalah atau fenomena tersebut maka penelitian ini membahas mengenai Bagaimana Komunikasi Persuasi Humas Dierektorat Jenderal Pajak dalam mensosialisasikan Program Pajak Bertutur melalui seminar di Universitas Nasional Jakarta dan mengetahui apakah komunikasi persuasi yang di gunakan Humas Dierektorat Jenderal Pajak pada Program Pajak Bertutur melalui seminar di Universitas Nasional Jakarta telah melakukan tahapan konsep proses komunikasi yang di kemukakan oleh (Perlofff :2003)

\section{METDODE PENELITIAN}

Metode penelitian yang digunakan oleh peneliti ini adalah metode penelitian kualitatif. Penelitian kualitatif bertujuan untuk menggambarkan, meringkas berbagai kondisi, berbagai situasi atau berbagai fenomena realitas yang tengah terjadi di masyarakat yang menjadi objek penelitian, dan berupaya menarik realtias itu kepermukaan sebagai suati ciri, karakter, sifat, model, tanda atau gambaran tentang kondisi, situasi ataupun fenomena tertentu (Bungin, 2007:68).

Metdode pengeumpulan data yang digunakan dalam penelitian ini adalah wawancara semistruktur dengan informan sebanyak enam orang yang terdiri dari eksternal dan internal responden. Sedangkan teknik pengumpulan data menggunakan data primer dan data sekunder.

\section{HASIL DAN PEMBAHASAN}

Dalam hasil penilitian ini dapat dilihat bahwa Direktorat Jenderal Pajak dalam melakukan komunikasi persuasi pada seminar pajak bertutur di Universitas Nasional Jakarta telah melakukan proses komunikasi yang di kemukakaan oleh (Perloff, :2008) bahwa di dalam proeses komunkasi persuasi memliki tahapan dimana persuade mempelajari pesan dari persuader. Dalam proses tersebut terdapat beberapa tahapan, yakni attention (perhatian), comprehension (pemahaman), learning (belajar), acceptance (penerimaan), dan retention (penyimpanan). Tahapan yang dikemukakan Perloff ini merupakan proses sebelum persuadee akhirnya memutuskan untuk merubah sikapnya, setelah mendapatkan paparan informasi atau argumen dari persuader. Hal itu pun selaras dengan tiga tujuan utama komunikasi persuasi yaitu membentuk tanggapan, memperkuat tanggapan, dan mengubah tanggapan. (Sumirat \& Suryana :2014).

Model proses komunikasi persuasi yang dilakukan oleh Direktorat Jenderal Pajak merupakan teori dasar sebelum dan di saat melakukan seminar pajak bertutur di Universitas Nasional Jakarta. Oleh karna itu, model proses komunikasi persuasi pertama yang di lakukan oleh Direktorat Jenderal pajak yaitu Attention (Perhatian).

Yang kedua adalah comprehension (Pemahaman), Persuader dalam hal ini Direktorat Jenderal Pajak di dalam seminar Pajak Bertutur di Universitas Nasional Jakarta, memberikan pemahaman secara rasional dan detail mengenai Komunikasi Persuasi Humas Direktorat Jenderal Pajak Melalui Seminar Pajak Bertutur Pada Mahasiswa Universitas Nasional Jakarta 
pesan informasi yang di sampaikan melalui seminar Pajak Bertutur, mengenai apa itu fungsi pajak dan manfaatnya.

Yang Ketiga ada Learning (Pembelajaran), Persuader dalam hal ini Direktorat Jenderal Pajak memberikan pembelajaran melalui program Pajak Bertutur ini mahasiswa di berikan pembelajaran mengenai sadar pajak, mahasiswa di tekankan untuk meningkatkan rasa cinta nasionalisme mereka, dari situlah muncul bahwa cinta nasionalisme bisa dilakukan salah satunya dengan berkewajiban membayar pajak.

Yang Kempat adalah Acceptance (Penerimaan), Persuader dalam hal ini Direktorat Jenderal Pajak sebelum seminar ia mencari tahu terlebih dahulu status sosial mahasiswa tersebut seperti apa agar informasi yang di berikan dapat diterima oleh mahasiswa.

Proses komunikasi Yang Kelima atau yang terakhir adalah Rettention (Penyaimpaian), Persuader dalam hal ini Direktorat Jenderal Pajak di dalam seminar pajak bertutur ini memberikan peyampaian secara berkala dan terus menurus melalui apapun untuk memberikan informasi tentang pajak.

Dalam pelaksanaan seminar pajak bertutur di Universitas Nasional Jakarta, humas Direktorat Jenderal Pajak menggunakan tiga aspek dasar persuasi yang di kemukaan oleh (Elvinaro :2010), bahwa Ethos (source credibility), memfokuskan pada kredebilitas sumber dalam meyampaikan pesan. Direktorat Jenderal Pajak menggunakan Persuader yaitu kepala kanwil DJP Jakarta Selatan II Bapak Edi Slamet Irianto sebagai ragukan lagi selain menjabat sebagai kanwil, rasa nasionalisme yang tinggi membuat audience terpengaruh terhadap apa yang di sampaikan oleh Persuader hal ini senada dengan aspek dasar persuasi kedua yaitu Pathos (emotional appeals), merujuk pada argument yang di dasarkan pada emosi membangkitkan perasaan-perasaan, seperti rasa takut, salah, amarah, humor, atau haru. (Elvinaro :2010). Lalu yang ketiga adalah Logos (logical appeals), merujuk pada appeals berdasarkan alasan yang logis. Persuder menjelaskan informasi mengenai pajak menggunakan komunikasi peruasi secara detail dan rasional, sehingga audience dapat dengan mudah memahami apa yang di sampaikan oleh Persuader.

\section{SIMPULAN}

Berdasarkan hasil penelitian kualitatif dengan teknik observasi, wawancara dan dokumentasi yang telah Kantor pusat Direktorat Jenderal Pajak yang terletak di Jalan Gatot Subroto Jakarta Selatan. Komunikasi Persuasi Humas Direktorat Jenderal Pajak melalui seminar Pajak Bertutur Pada Mahasiswa Universitas Nasional Jakarta, diperoleh kesimpulan yaitu Komunikasi Persuasi yang dilakukan humas Direktorat Jenderal Pajak melalui seminar di kampus Universitas Nasional Jakarta sudah memenuhi cara dengan melakukan 5 tahapan proses komunikasi persuasi yaitu, Attention (Perhatian), Comperhension (Pemahaman), Learning (Pembelajaran), Acceptance (Penerimaan), Rettention (Penyimpanan). 


\section{DAFTAR PUSTAKA}

Buku :

Brata, A. A. (2003). Dasar - Dasar Pelayanan Prima. Jakarta: Elex Media Komputindo.

Bungin, B. (2007). Penelitian Kualitati.. Jakarta: Kencana Prenada Media Group.

Elvinaro, A. (2010). Metodologi Penelitian untuk Public Relations Kuantitatif dan Kualitatif. Bandung: Simbiosa Rekatama Media.

Perloff, R. M. (2003). The Dynamics of Persuasion; Communication and Attitudes in the 21st Century. New Jersey: Lawrence Erlbaum Associates Publisher.

Perloff, R. M. (2008). The Dynamics of persuasion: Communication and attitude in the 21st (3rd.ed). New York: Lawrence Erlbaum Associates Inc.

Ruslan, R. (2007). Manajemen Public Relations dan Media Komunikasi.

Rakhmat, J. (2008). Psikologi Komunikasi. Bandung: PT. Remaja Rosdakarya.

Severin \& Tankard, W. (2007). Teori Komunikasi: Sejarah, Metode dan Terapan di Dalam Media Massa. Jakarta: Kencana.

Sumirat \& Suryana, S. (2014). Komunikasi Persuasif. Banten: Universitas Terbuka.

\section{Artikel :}

Pajak Bertutur, siapkan generasi emas yang sadar pajak. (2017) di akses dari www.pajak.go.id:http://www.pajak.go.id/content/ article/pajak-bertutur-siapkan-generasi-emasyang-sadar pajak

Target Penerimaan Negara . (2018) di akses dari: https://www.cnnindonesia.com/ekonomi/2017081 6070709-78-235041/jokowi-targetkanpenerimaan-negara-di-2018-tembus-rp1878-t

\section{Jurnal :}

Syamsurizal. (2016). Strategi Komunikasi Persuasif Dalam Aktifitas Pemasaran (Studi Deskriptif Komunikasi Persuasif Presenter (Staff Pemasaran) dalam Merekrut Calon Mahasiwa baru di Politeknik LP3I Jakarta) 